\title{
ARGUMENTO CÍNICO-MORAL
}

\section{Resumo}

Jair Pinheiro Doutor em Ciência Política; Membro do NEILS - Núcleo de Estudos de Ideologias e Lutas Sociais, do Programa de Estudos PósGraduados - PUC/SP; Professor do Departamento de Ciências Sociais na UNINOVE

Este breve ensaio apresenta uma crítica aos argumentos de natureza moral em favor da guerra dos EUA contra o Iraque, procurando evidenciar seu caráter falacioso e os verdadeiros objetivos de natureza geopolítica que animaram o conflito.

Palavras-chave: cidadania; direito; guerra.

\begin{abstract}
This brief essay presents a critique of moral arguments on behalf of US war against Iraq. It is an attempt to highlight the false reason pleaded for war and the true geopolitical target that sustained the conflict.
\end{abstract}

Key words: citizenship; law; war.

$\mathrm{M}_{\mathrm{d}}^{\mathrm{e}}$ eu objetivo é apenas apresentar breves comentários a um tipo de argumento - título deste artigo - justificador da guerra contra o Iraque.

Durante o conflito, a imprensa publicou diversos argumentos favoráveis e contrários à investida estadunidense. Entre os posicionamentos favoráveis, um está baseado no imperativo moral, qual seja, o de que o fato de Saddam Hussein ter sido um contumaz e sangüinário ditador bastaria para justificar moralmente a guerra. Assim, a guerra passa a ser feita em nome e memória das vítimas da ditadura, isto é, desencadeia um processo de legitimação do uso da força por uma causa superior que tem como valor central a liberdade. ${ }^{1}$

1 Folha de São Paulo, de 11 ago. 2002. Henry Kissinger: "Num discurso eloqüente proferido em West Point, em junho, Bush enfatizou que as novas armas de

$\mathrm{O}$ argumento seria perfeito se... Se esquecêssemos que o destruição em massa já não permitem que os EUA se dêem ao luxo de ficar aguardando um ataque; 'precisamos estar prontos para entrar em ação antecipada e
preventiva quando isso for mesmo governo que utiliza o imperativo moral para a deposição de um ditador também apóia o mesmo Saddam Hussein em sua preventiva quando isso for investida contra o Irã, o regime confessional e autoritário da Arábia $\begin{aligned} & \text { necessario } \\ & \text { liberdade"." }\end{aligned}$ 
Saudita, o Taleban contra o exército Soviético, o golpe (ironicamente num outro 11 de setembro) de Pinochet contra Allende - eleito democraticamente -, o governo assassino de Ariel Sharon $^{2}$ e o descumprimento sistemático, por parte de Israel, de todas as resoluções da ONU que determinam a desocupação dos territórios tomados aos palestinos.

Esses exemplos da história recente bastam para evidenciar que o critério de ação do governo estadunidense - como, de resto, de qualquer outro governo - não se ampara em nenhum imperativo moral, e sim em seus interesses econômicos e geopolíticos, embora tais imperativos possam ser - e, de fato, são - ideologicamente articulados, visando à legitimação de uma política de Estado.

Como se opera tal articulação? Uma das características da política internacional contemporânea é o envolvimento do que podemos denominar, embora sem rigor metodológico, de opinião pública mundial (MATELLART, 1994). Em outras palavras, a legitimação da ação de um governo no cenário global não depende apenas de acordos bilaterais e/ou multilaterais, mas também da persuasão de indivíduos espalhados por todo o planeta. Opinião pública, tanto nacional quanto internacional, não é um conjunto de indivíduos emitindo juízos de realidade conforme sua capacidade de discernimento, como faz crer a defesa singela de uma política de Estado baseada em pesquisa de opinião: ela é, sobretudo, um conjunto de empresas de comunicação cuja estratégia de 'produção da notícia', entre outros produtos, está pautada nos seus interesses mercadológicos e compromissos políticos. Não por acaso, paralelamente ao debate sobre a guerra e suas razões, discutiu-se a cobertura da guerra pela mídia, chegando-se à conclusão de que um dos vencedores foi a rede de televisão Fox News, por sua cobertura francamente favorável às posições do governo e pela conquista de uma faixa mais ampla do mercado de comunicação. ${ }^{3}$

No caso particular da guerra contra o Iraque, a despeito de milhões de pessoas terem saído às ruas de cidades espalhadas por todo o mundo em protesto contra a guerra, não se registrou, no hemisfério ocidental, manifestação de apoio a Saddam Hussein ou aos valores que ele alegava representar. Ao contrário, os manifestantes apoiavam-se em valores ocidentais e, em alguns casos, naqueles alegados pelo governo estadunidense para ir à guerra. 
Evidentemente, os valores do Ocidente não constituem um conjunto homogêneo. Ao contrário, incluem-se neste conjunto heterogêneo, entre outros, o livre comércio, a eliminação da propriedade privada dos meios de produção e a universalidade dos direitos humanos, para limitar-me aqui a exemplos localizados em posições diversas do espectro ideológico ocidental. Daí porque a diversidade de posições em relação à guerra basear-se no mesmo conjunto de valores, ou seja, sem necessária relação entre a defesa de determinados valores e o posicionamento favorável ou contrário à guerra sob a perspectiva de qualquer agente particular. Como essa premissa teórica dificilmente poderá ser negada e aos analistas não é dado o direito de ignorar os fatos acima mencionados, segue que a defesa da posição de base moral do governo dos EUA se transforma em argumento cínico-moral, pois sob um princípio moral escondese a defesa de uma política imperialista responsável direta ou indiretamente pela morte de milhões de pessoas.

Não bastasse isso, esse mesmo governo, sob o arbítrio da sua política de segurança nacional, mantém encarcerados na base de Guantánamo, em Cuba, centenas de prisioneiros da guerra no Afeganistão, aos quais é negada qualquer jurisdição. Enfim, o país cuja revolução liberal do século XVIII, ao lado da Revolução Francesa, tornou-se o paradigma dos direitos universais do homem, criou a figura do não-cidadão, ao qual se pode aplicar toda sorte de violência sem cometer um atentado à noção de direito.

A rigor, em todos os países capitalistas há um contingente, maior ou menor, de não-cidadãos, na medida em que são privados de direitos básicos, por absoluta falta de recursos para consumá-los, além de, contrariamente ao que se apregoa, haver espaços sociais em que a cidadania como expressão da vontade é negada, pois nem todas as formas associativas constituem uma associação entre cidadãos livres. Como nos lembra Santos (1995, p. 239),

no capitalismo há uma forma de associação 'especial' que só cinicamente pode conceber-se como voluntária e onde a formação da vontade 4 Assinale-se que participação, neste caso, significa a prerrogativa de intervir autonomamente num

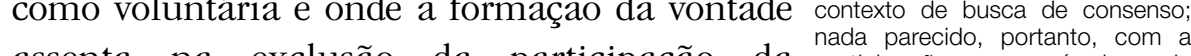
assenta na exclusão da participação da participação nos círculos de esmagadora maioria dos que nela 'participam', promovidos $\underset{\text { pela motivação }}{\text { empresa }}$ isto é, a empresa enquanto unidade básica da capitalista e que servem, entre organização econômica da produção capitalista. ${ }^{4}$ identificar recalcitrantes. 
Portanto, o caso dos prisioneiros de Guantánamo não escandaliza pela novidade que não representa, mas pela contradição que induz o Estado de Direito a criar o seu outro - o não-direito.

O debate que se processou no período apresentou dois tipos de argumento cínico-morais. O primeiro consiste em apresentar como necessária a relação entre a defesa dos direitos humanos das vítimas de Saddam Hussein e a posição do governo Bush, sofisma que visava a ocultar a articulação ideológica para legitimar o uso, pelos EUA, de seu poderio bélico como melhor lhe aprouvesse. Esse sofisma adquire ares de seriedade principalmente quando, em seu apoio, se aduz a alegação de que a posição contrária à guerra baseava-se num anti-americanismo tolo e infantil, pois os mesmos indivíduos não abririam mão de comer hamburger e tomar Cocacola, símbolos da cultura daquele país.

O segundo tipo de argumento cínico-moral, mais sofisticado, consiste em estabelecer uma identidade entre os valores da sociedade burguesa e a universalidade do ser humano. Nesse ponto, o choque entre os valores proclamados e a realidade excludente da economia capitalista provoca um curto-circuito no pensamento dos analistas comprometidos com a defesa do establishment, levando-os a uma produção crescente de argumentos que sempre projeta a universalização do ethos burguês num futuro incerto, configurado na conjunção condicional 'se' se os países cuja população, em sua maioria, vive sob o autoritarismo e a pobreza, adotarem os valores do livre comércio e da democracia representativa, ${ }^{5}$ em pouco tempo atingirão a prosperidade e o bem-estar social. E aqueles que já adotaram esses valores e ainda não chegaram à prosperidade e ao bem-estar? A resposta é simples: cometeram graves erros operacionais. Assim, volta-se ao condicional.

Esses analistas não percebem - ou percebem e não admitem - que a democracia realmente existente é um regime de dominação de classe (SAES, 1993), ou, por outras palavras, sua forma (sufrágio universal) e seu conteúdo (distribuição desigual dos recursos políticos) apresentam uma contradição insolúvel nos limites da forma social capitalista, pois está assentada na propriedade privada dos meios de produção, base do antagonismo de classe. 
Destarte, a possibilidade de uma relação necessária entre um posicionamento relativo à guerra e um imperativo moral está na perspectiva da universalidade do ser humano e, portanto, contrária à guerra, ou seja, às causas dela. Isso supõe a supressão do antagonismo de classe, que opõe parcela minoritária dos indivíduos a outra majoritária como contendores, em razão de seus interesses materiais; além disso, impõe o deslocamento de outros particularismos (religioso, étnico etc.) para a esfera privada ou da comunidade imediata (MARX, 2000), nas quais a possibilidade de reivindicação de direitos, baseada em tais identidades históricosociais, reitere simultaneamente seu caráter particularista e seu fundamento pressuposto, isto é, a comunidade universal de homens e mulheres livremente associados.

Evidentemente, enquanto essa comunidade não se constitui em formas sociais efetivas, àqueles que se opõem à guerra resta apenas o posicionamento derivado de uma perspectiva particular. Trata-se, então, de identificar a força social cuja posição particular pode colocar a perspectiva de realização histórico-social da comunidade universal de homens e mulheres, livremente associados, como possibilidade lógica e concreta. Certamente, essa comunidade universal não se identifica com a perspectiva da sociedade burguesa em geral, nem com a dos EUA, em particular.

\section{Referências}

MARX, Karl. Questão judaica. São Paulo: Centauro, 2000.

MATTELART, Armand. Comunicação-mundo bistória das idéias e das estratégias. Petrópolis: Vozes, 1996.

SAES, Décio. Democracia. São Paulo: Ática, 1993.

SANTOS, Boaventura S. Pela mão de Alice: o social e o político na pós-modernidade. São Paulo: Cortez, 1995. 
